\title{
The Dynamics of the Skin Temperature of the Dead Sea
}

\author{
Roni Nehorai, ${ }^{1,2}$ Nadav Lensky, ${ }^{2}$ Steve Brenner, ${ }^{1}$ and Itamar Lensky ${ }^{1}$ \\ ${ }^{1}$ Department of Geography and Environment, Bar-Ilan University, 52900 Ramat-Gan, Israel \\ ${ }^{2}$ Geological Survey of Israel, 30 Malkhe Israel Street, 95501 Jerusalem, Israel \\ Correspondence should be addressed to Itamar Lensky; itamar.lensky@biu.ac.il
}

Received 1 January 2013; Revised 28 May 2013; Accepted 15 June 2013

Academic Editor: Lian Xie

Copyright (C) 2013 Roni Nehorai et al. This is an open access article distributed under the Creative Commons Attribution License, which permits unrestricted use, distribution, and reproduction in any medium, provided the original work is properly cited.

\begin{abstract}
We explored the dynamics of the temperature of the skin layer of the Dead Sea surface by means of in situ meteorological and hydrographic measurements from a buoy located near the center of the lake. The skin temperature is most highly correlated to air temperature (0.93-0.98) in all seasons. The skin temperature is much less correlated to the bulk surface water temperature in the summer $(0.80)$, when the lake is thermally stratified, and uncorrelated in the winter, when the Dead Sea is vertically mixed. Low correlations were found between the skin temperature and the solar radiation and wind speed in all seasons. The skin, with its low thermal inertia, responds immediately to the atmospheric forcing. Heat fluxes across the sea surface are also presented. The high correlation of skin temperature to air temperature with minimal time lag is a result of the nearly immediate response of the thin skin layer to the surface heat fluxes, primarily the sensible heat flux.
\end{abstract}

\section{Introduction}

Sea surface temperature (SST) is a critically important parameter in the study of ocean-atmosphere interactions. SST has a major role in atmospheric models, weather forecasting, climate change models, and energy balance calculations. SST can be measured from satellites and represents a very thin boundary layer $(\sim 10 \mu \mathrm{m}$ skin layer $)$ between the turbulent ocean and atmospheric layers. At this boundary layer, exchanges of sensible and latent heat occur, and long-wave radiation is emitted and absorbed [1]. Different processes act on the skin layer and on the water body beneath it (bulk layer), resulting in a difference between the skin and bulk temperatures.

Saunders [2] presented a simple theory in which the difference between bulk temperature and skin temperature, commonly termed "the skin effect" $(\Delta T)$, is proportional to the heat flux (including sensible, latent, and long wave radiative heat fluxes from ocean to atmosphere) and inversely proportional to the kinematic stress (wind friction); the theory is limited to conditions of negligibly low solar radiation and excludes very low wind intensity. One of the predictions of this model is that the ocean is usually covered with a "cool skin". The skin effect is estimated using measured in situ bulk temperature and long wave radiation from which the skin temperature is calculated [3].

The effects of wind, waves, and the upper layer mixing on the boundary layer have been investigated [3-5]. These studies have shown that wind mixes the upper layer, cooling the skin layer, and that breaking waves momentarily destroy the skin layer, which reestablishes itself within less than one second [6].

Physical processes that control the skin effect vary throughout the seasonal and diurnal cycles. Emery et al. [1] described three mixing regimes in the water body affecting the skin effect: free convection, forced convection driven by wind stress, and forced convection driven by microscale wave breaking. They used different models to represent the physics of the skin layer and applied the models to measured data sets. Although these models reproduced the overall variability of the measured skin effect, nevertheless most of the variance was not explained $\left(R^{2}=0.28\right.$ was the highest of all models.)

Over the last decade there has been an improvement in the calibration of satellite measured SST to in situ measurements. Much of this work is coordinated through the Group for High Resolution Sea Surface Temperature (GHRSST), using radiative transfer models $[7,8]$ or regression-based retrieval [9-11]. 
Little is known about the dynamics of the skin layer and the skin effect of the Dead Sea (Figure 1(a)). The Dead Sea is a hypersaline lake with a reduced evaporation rate due to the low water activity (the vapor pressure of the brine is about 0.7 of that of pure water at the same temperature) [12] and is the warmest large water body on Earth. Nehorai et al. [13] characterized the Dead Sea surface temperature using sequences of 15-minute interval satellite images and in situ measurements of wind speed, solar radiation, and air temperature. They found that at night the SST over the Dead Sea is relatively uniform, whereas during daytime the spatial variability is much larger. They concluded that the horizontal uniformity of the Dead Sea surface temperature during nighttime is due to the strong night winds that cause a vertical mixing of the upper few meters. During the day, the skin temperature rises due to intense solar radiation and the low wind speeds. The skin layer is very sensitive to wind intensity [6]. In the Dead Sea, even weak winds $(<5 \mathrm{~m} / \mathrm{s})$ during daytime locally destroy the skin layer, causing the observed nonuniformity in SST [13]. In contrast, during nighttime strong winds $(>5 \mathrm{~m} / \mathrm{s})$ associated with the Mediterranean Sea breeze intensify vertical mixing over the entire Dead Sea surface, which results in uniform SST over the Dead Sea. SST in closed and stratified lakes can be influenced by wind driven upwelling events, as indicated in thermistor chains and thermal infrared images when the cooler epilimnion or metalimnion reaches the surface (e.g., in Lake Tahoe, [14]). Thermistor chain data in the Dead Sea [15-18] and satellite thermal images [13] show that the upper layer is well mixed, the thermocline depth throughout the stratified season is $\sim 25 \mathrm{~m}$, and cooler hypolimnion water does not reach the sea surface during typical wind events. The circulation in the Dead Sea was previously studied with a few short term, sporadic observations. Neev and Emery [19] and Emery and Csanady [20] measured currents in 1959, when the Dead Sea was meromictic and had two connected basins, a deep northern basin and a shallow southern basin. Since then the northern and southern basins have disconnected due to the dropping sea level, and the Dead Sea has switched to holomictic conditions due to the increasing salinity of the upper layer.

In this paper we use in situ measurements of skin, bulk and air temperatures, solar radiation, and wind speed measured from a buoy located near the center of the Dead Sea to explore the diurnal and seasonal cycles and the major forcing of the skin temperature.

\section{Data and Methods}

Meteorological data, including air temperature $\left(T_{a}\right)$, wind speed (Ws), and solar radiation ( $\mathrm{Ra})$, were collected every 20 minutes at $3.7 \mathrm{~m}$ above the sea surface from a hydrometeorological buoy operated by Israel Oceanological and Limnological Research (IOLR), located $\sim 5 \mathrm{~km}$ offshore of Ein Gedi, near the center of the lake (Figures 1(a) and 1(b)). All measuring instruments were manufactured by Aanderaa, as presented in $[16,21]$.

Bulk temperature $\left(T_{b}\right)$ was measured using a thermistor placed at a depth of $5 \mathrm{~cm}$. The thermistor was tied to a small

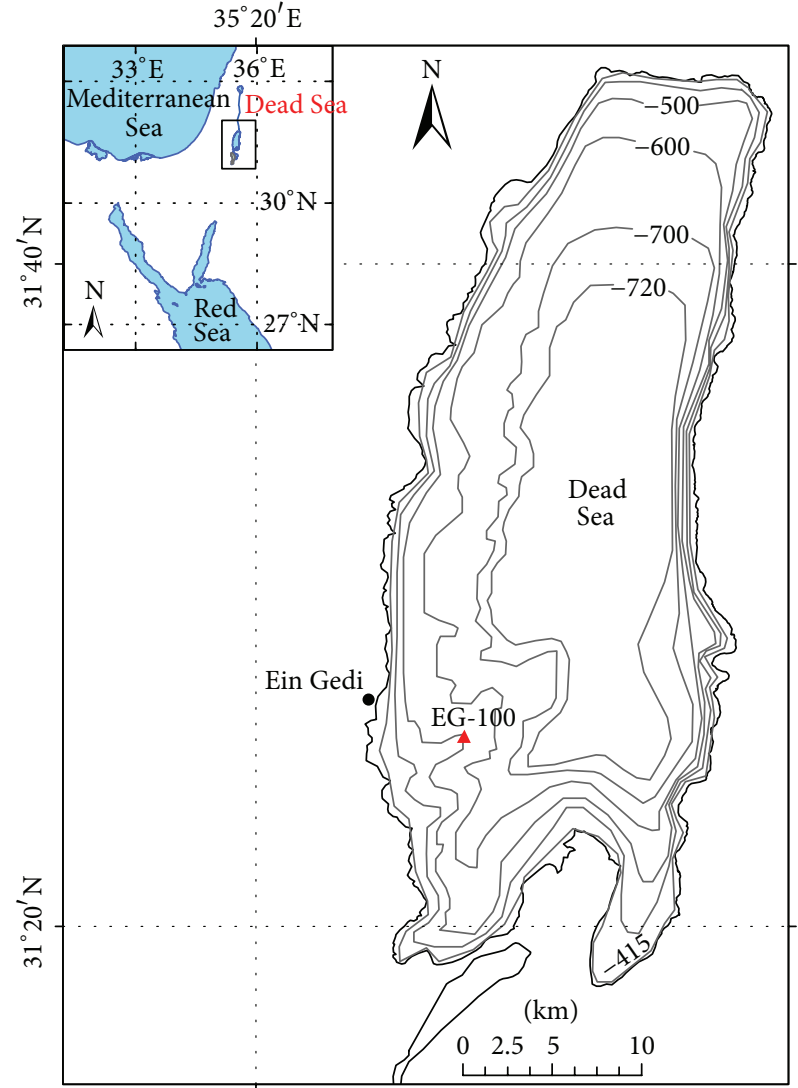

- Hydrometeorological station

- Batymetry

(a)

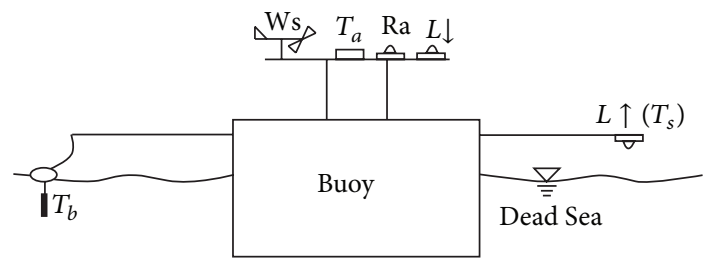

(b)

Figure 1: (a) Map of the Dead Sea, including the hydrometeorological station (red triangle) mentioned in the text. (b) Schematic diagram of the hydrometeorological buoy showing the relevant instruments. This buoy measured: $T_{s}$ : skin layer temperature, Ws: wind speed; Ra: short wave radiation; $T_{a}$ : air temperature; $T_{b}$ : bulk temperature; $L$ : long wave radiation.

buoy $2 \mathrm{~m}$ away from the hydrometeorological buoy to avoid the influence of the hydrometeorological buoy on the thermal structure of the top $5 \mathrm{~cm}$ (Figure 1(b)). We used a thermistor (Solinst model 3001, levelogger junior) with an accuracy of $\pm 0.1^{\circ} \mathrm{C}$ and a temperature resolution of $0.1^{\circ} \mathrm{C}$. Another thermistor was located at a depth of $1 \mathrm{~m}$.

The skin temperature $\left(T_{s}\right)$ was measured using two longwave radiometers (Kipp \& Zonen, CGR4) installed on the buoy. The CGR 4 radiometer is sensitive to infrared radiation in a wavelength range from 4.5 to $42 \mu \mathrm{m}$ (it has an extremely 
low window heating offset and diamond-like coating for optimal protection against environmental influences and low temperature dependence of sensitivity). The downward directed radiometer was placed at the edge of an extension arm $2 \mathrm{~m}$ away from the buoy and one meter above the water surface, minimizing the atmospheric effects on the measurements and the effect of the buoy on the fine thermal structure. The second radiometer was placed next to the meteorological instruments ( $3.7 \mathrm{~m}$ above the water surface), directed upward. It received the downward long-wave radiation emitted from the atmosphere $(L \downarrow)$. The downward directed radiometer received the total long-wave radiation flux $(L \uparrow)$ consisting of the radiation emitted from the sea surface and the radiation reflected upwards from the sea surface. To calculate $T_{s}$ we used the following equation:

$$
L \uparrow-L \downarrow(1-\varepsilon)=\varepsilon \times \sigma \times T_{s}^{4},
$$

where $\varepsilon=0.975$ is the water emissivity (and absorption); $(1-\varepsilon)$ is the water reflectance, and $\sigma$ is the Stefan-Boltzmann constant.

We used cross correlation to analyze the correlation and time lag between $T_{s}$ and the other measured quantities $\left(T_{a}\right.$, $T_{b}$, Ws, and $\mathrm{Ra}$ ). Since the skin layer is very thin, with a very short thermal response time (seconds), we expected that the measured quantity that showed the minimum time lag and the highest correlation to be indicative of the major forcing of the skin layer.

Heat fluxes were calculated following Lensky et al. [12], which include the required adaptations to the unique conditions of the Dead Sea. In this work we measured the net radiation, $Q_{R N}$, using four radiometers; short wave and long wave directed upward and downward. The contradiction will be explained in the next point. Latent heat $\left(Q_{L}\right)$ and sensible $\left(Q_{S}\right)$ heat were calculated using bulk formulas ((2) and (3), resp.), with the numeric values suitable for the Dead Sea, accounting for the heat and water balances:

$$
\begin{gathered}
Q_{L}=f(w) \cdot\left(e_{b r}-e_{a}\right), \\
Q_{S}=c_{b} \cdot \frac{P}{1000} \cdot f(w) \cdot\left(T_{s}-T_{a}\right),
\end{gathered}
$$

where $e_{b r}$, is vapor pressure of the brine, calculated using the water activity of the brine $(\beta \sim 0.7), e_{a}$ is the atmospheric vapor pressure, $c_{b}$ is the Bowen constant $\left(0.61 \mathrm{hPa} /{ }^{\circ} \mathrm{C}\right), P$ is the air pressure $(\mathrm{hPa})$, and $f(w)$ is the wind function (4) with the parameterization accounting for energy and mass balance of the Dead Sea $[12,15]$ :

$$
f(w)=0.483 \cdot\left(9.2+\left(0.46 \cdot \mathrm{Ws}^{2}\right)\right) \text {. }
$$

The Bowen ratio, $B,(5)$ is also presented in the results:

$$
Q_{S}=Q_{L} \cdot B \text {. }
$$

The net heat $\left(Q_{n}\right)$ is calculated using two independent approaches: as the residual heat flux, and from the change in the heat storage of the lake ((6) and (7), resp.):

$$
\begin{gathered}
Q_{n}=Q_{L}+Q_{S}+Q_{R N}, \\
Q_{n}=-C_{p} \cdot m_{t} \cdot \frac{\Delta T}{\Delta t},
\end{gathered}
$$

where $C_{p}$ is the specific heat capacity, $m_{t}$ is the total mass, and $\Delta T / \Delta t$ is the rate of temperature change.

\section{Results}

3.1. The Diurnal and Seasonal Cycles of the Skin Effect. The major finding of this study is that the diurnal cycle of $T_{s}$ is most highly correlated to $T_{a}(0.93-0.98)$ with a minimal time lag in all seasons. It is much less correlated to $T_{b}$ with a larger time lag. $T_{s}$ is even less correlated to Ws, and Ra with even higher time lags. Figure 2 presents the time series of all measured quantities of four representative days in winter, summer, and autumn. Figure 3 presents scatter diagrams of $T_{s}$ versus $T_{a}, T_{b}$, Ws and $\mathrm{Ra}$ in the three seasons. The correlations are computed for five, 45, and 17 days in the summer, winter, and autumn, respectively. Figures 4 and 5 present the cross correlations of these pairs. Figure 6 is a schematic diagram of the diurnal and seasonal cycles of temperature profiles, from the air, through the skin to the different layers of the main water body. Figure 7 presents the heat fluxes time series.

3.2. Correlation of $T_{s}$ to $T_{b}$ and $T_{a}$. During the winter, convection fully mixes the Dead Sea; therefore, the water temperature is almost uniform throughout the entire water column $(300 \mathrm{~m})$. The diurnal amplitude of $T_{b}$ is $\sim 0.2^{\circ} \mathrm{C}$, whereas $T_{s}$ and $T_{a}$ show much larger amplitudes of $2-4^{\circ} \mathrm{C}$. Throughout the day $T_{b}$ is higher than $T_{a}$ by $1-5^{\circ} \mathrm{C}$, leading to a continuous cooling of the entire water column through the skin at a rate of $\sim 0.02^{\circ} \mathrm{C} /$ day. The skin layer is cooler and saltier due to evaporation and with higher density than the layers underneath and is therefore unstable. This difference drives the winter convection and cooling. Accordingly, $T_{s}$ and $T_{b}$ exhibit practically no correlation in winter $(-0.17)$, whereas the correlation between $T_{a}$ and $T_{s}$ is very high (0.97), with practically no time lag (see Figures $4(a)$ and 5).

In the summer, the Dead Sea is stratified with an upper mixed layer above a sharp thermocline at a depth of 20-30 m. The upper diurnal layer with a thickness of $\sim 5 \mathrm{~m}$ develops due to the solar heating and mixes at night with the layer beneath it due to density changes (Figure 6) [16]. As in the winter, $T_{s}$ is most highly correlated to $T_{a}(0.93)$ with no significant time lag (Figures $4(\mathrm{~b})$ and 5 ). The correlation between $T_{b}$ and $T_{s}$ is highest in the summer (0.79) with a time lag of one hour. This is higher than the correlation of $T_{s}-\mathrm{Ra}$ and $T_{s}-$ Ws (Figures 4 and 5). The diurnal amplitude of $T_{b}$ is smaller than $T_{a}$ and $T_{s}\left( \pm 1^{\circ} \mathrm{C}\right.$ and $\pm 2-3^{\circ} \mathrm{C}$, resp., Figure $\left.2(\mathrm{~b})\right)$, but still significantly higher than in the winter, representing stronger coupling between the sea and the atmosphere during the stratified period.

In the autumn, the Dead Sea is still stratified, but the stability of the upper layer decreases together with the decrease of water temperature and its reduced diurnal amplitude. $T_{s}$ highly correlates to $T_{a}(0.98)$ with no time lag and correlates less to $T_{b}(0.68$, Figures $4(\mathrm{c})$ and 5$)$. The correlation of $T_{b}$ to $T_{s}$ is higher in the summer than in autumn (Figures 4(b) and $4(\mathrm{c})$ ), probably due to the weaker incoming solar radiation (Figures 2(e) and 2(f)), which results in the reduced diurnal amplitude of $T_{b}$ in autumn. The cooling rate of $T_{b}$ in the autumn is $\sim 0.18^{\circ} \mathrm{C} /$ day, which is ten times larger than in 

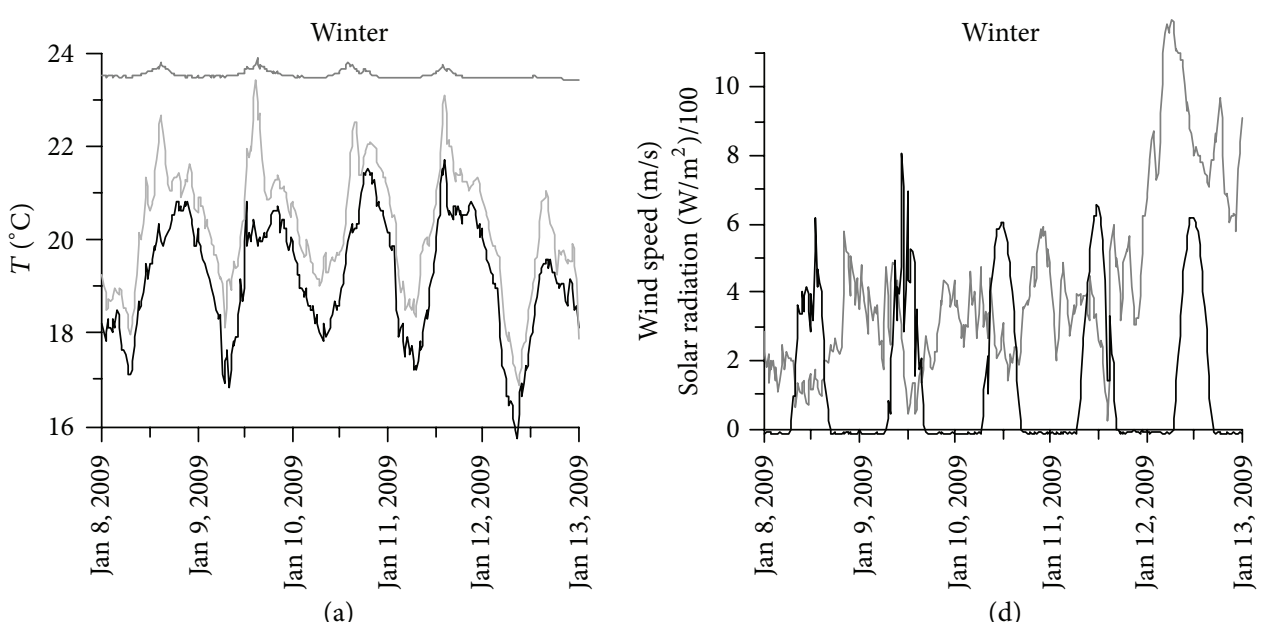

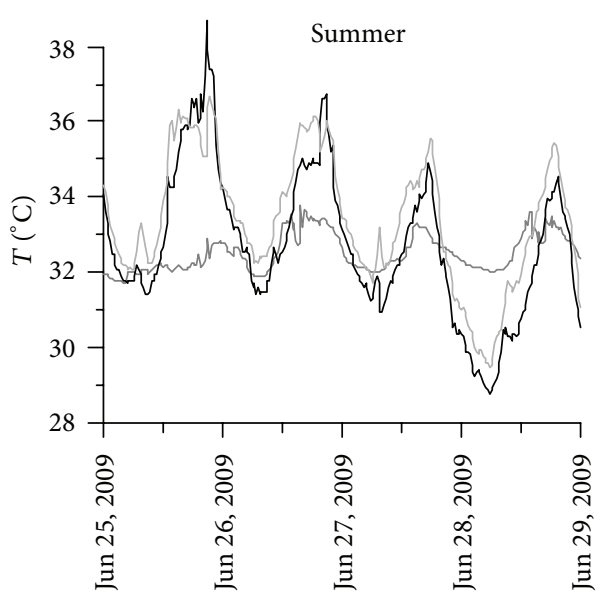

(b)

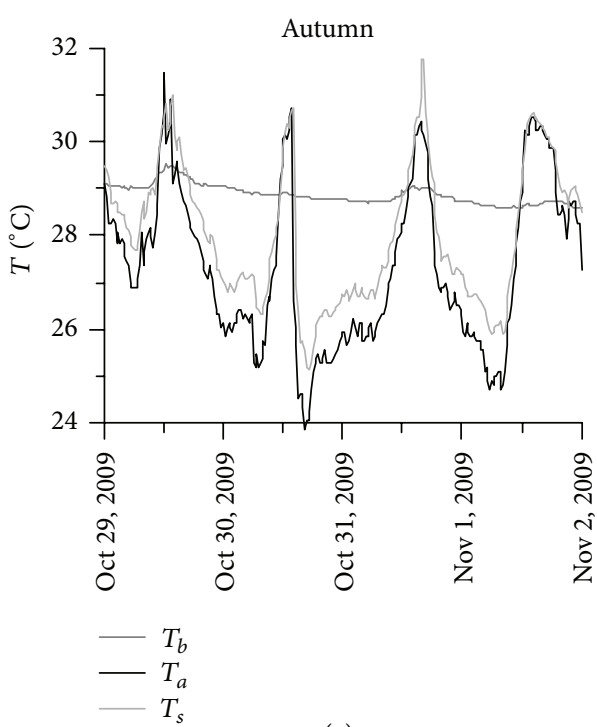

(c)

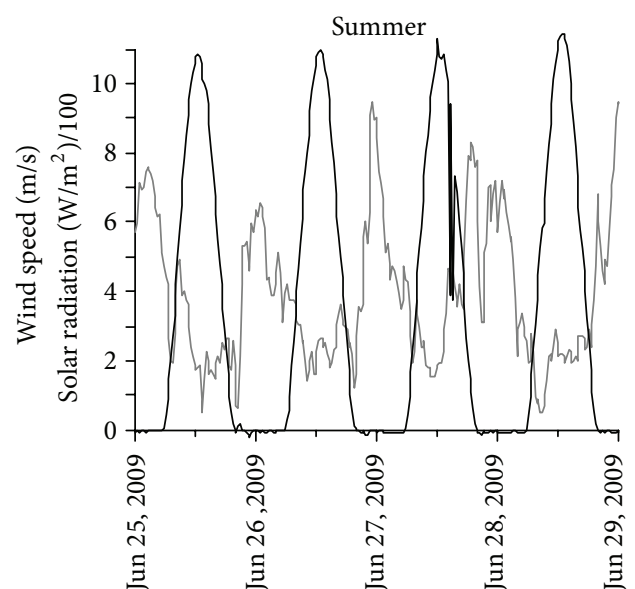

(e)

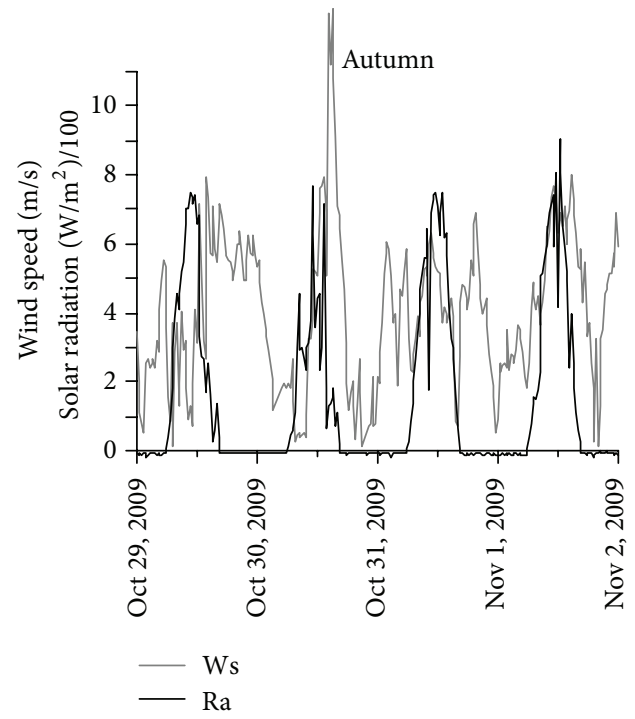

(f)

Figure 2: Time series of bulk $\left(T_{b}\right)$, skin $\left(T_{s}\right)$, air temperatures $\left(T_{a}\right)$, wind speed (Ws), and solar radiation (Ra) during four representative days in winter (a), (d), when the water column is homogeneous; and summer and autumn (b), (e) and (c), (f), respectively, when the water column is stratified. 


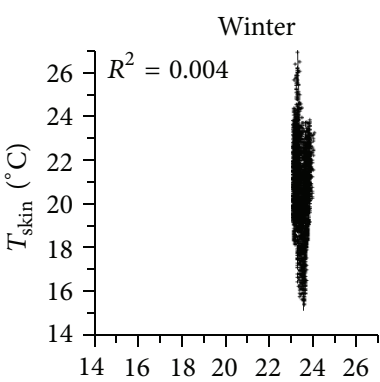

(a)

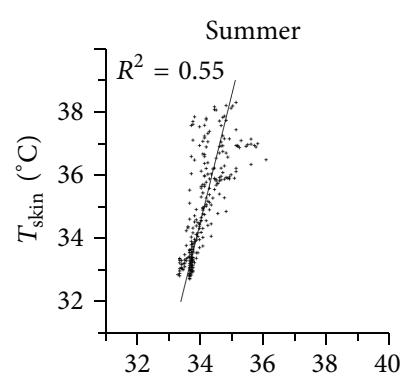

(e)

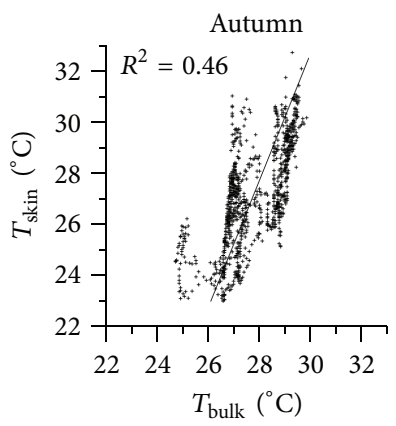

(i)

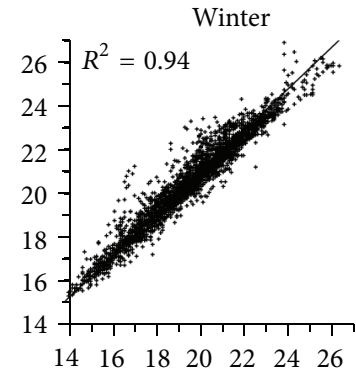

(b)

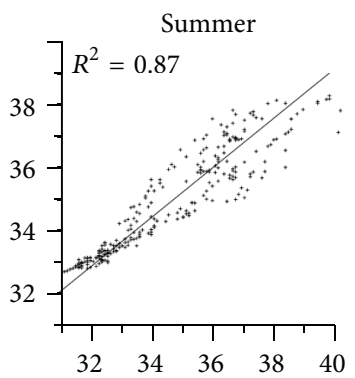

(f)

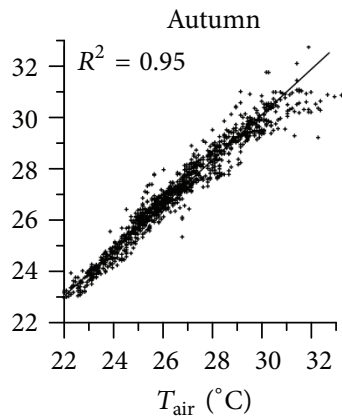

(j)

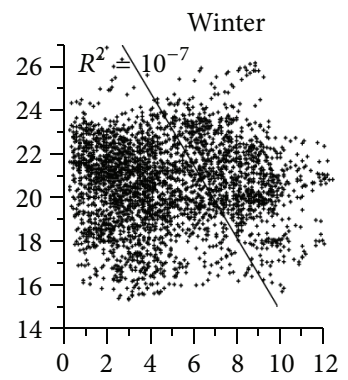

(c)

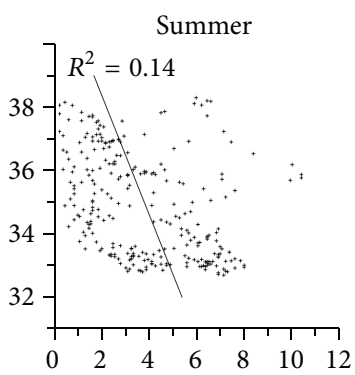

(g)

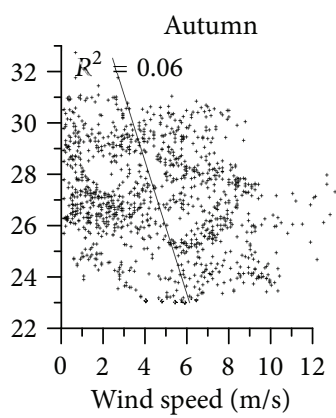

$(\mathrm{k})$

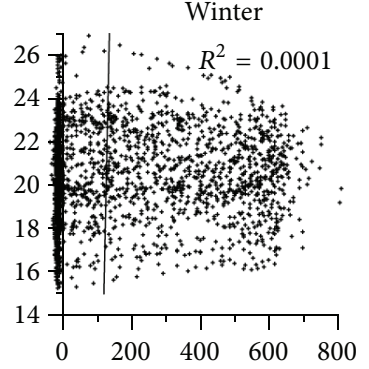

(d)

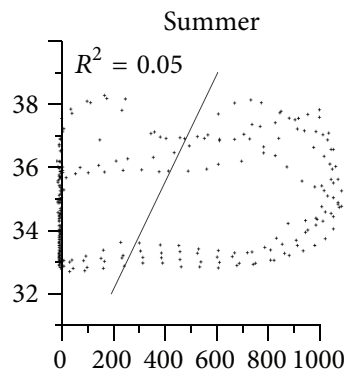

(h)

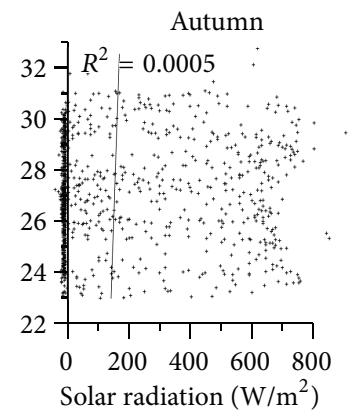

(l)

FiguRE 3: Correlations between surface, bulk water temperature, air temperature, wind speed, and solar radiation in winter ((a), (b), (c), (d))-(22 Dec 2008-14 Jan 2009); summer ((e), (f), (g), (h))—(25-29 Jun 2009); and autumn ((i), (j), (k), (l))—(27 Oct -10 Nov 2009$).$

winter. The more efficient cooling of $T_{b}$ in autumn relative to winter is due to the difference in the thickness of layer interacting with the atmosphere, which in the winter is ten times thicker than in autumn ( 300 $\mathrm{m}$ and $\sim 30 \mathrm{~m}$, resp.).

3.3. Correlation of $T_{s}$ to Ra and Ws. Low correlations and significant time lags were found between $T_{s}$ and the atmospheric forcing (Ws and Ra) in all seasons (Figures 3, 4, and 5). Ra and $T_{s}$ both show a diurnal cycle with high values during daytime and low values at nighttime (Figures 2(d), 2(e), and 2(f)). However, there is a lag of 4-5 hours in which Ra precedes $T_{s}$. In the scatter diagram this is seen as a counterclockwise cycle, as is best demonstrated in Figures 3(h) and 2(e). From sunrise (no solar radiation and $T_{s} \sim 33^{\circ} \mathrm{C}$ ), the solar radiation increases to $\sim 1100 \mathrm{Wm}^{-2}$ with minor changes in $T_{s}$. At noontime, $T_{s}$ increases rapidly to about $37^{\circ} \mathrm{C}$, gradually decreases to $36^{\circ} \mathrm{C}$ at sunset, and falls back to $33^{\circ} \mathrm{C}$ at nighttime.

The wind speed is even less correlated to $T_{s}(0$ to -0.71$)$. The correlation of $T_{s}-\mathrm{Ws}$ is negative, with a time lag of 2-3.3 hours. Negative shifts in $T_{s}-$ Ws occur while the $T_{s}-T_{a}$ shift is positive. This is due to strong dry winds at nighttime, which cool the skin layer by increased evaporation.

3.4. Heat Fluxes. Heat fluxes were calculated for 45 days during the winter. Figure 7 presents a time series of the heat flux components and the main meteorological parameters determining the fluxes. The net radiation (Figure $7(\mathrm{a})$ ) has a typical diurnal cycle with high net radiation during the day and a repeating cycle with a very weak trend throughout the period. The latent and sensible heat fluxes are presented in Figure 7(b). The latent heat flux is characterized by periods of high fluxes (high evaporation rate), which is mostly related to the wind intensity (Figure $7(f)$ ). The sensible heat flux has a clear diurnal cycle with higher flux during the night, when the air temperature is lower than the bulk water temperature by up to $8^{\circ} \mathrm{C}$ (Figure $7(\mathrm{e})$ ). Note that the skin and air temperatures are highly correlated, as mentioned above, whereas the bulk water temperature shows a negligible 


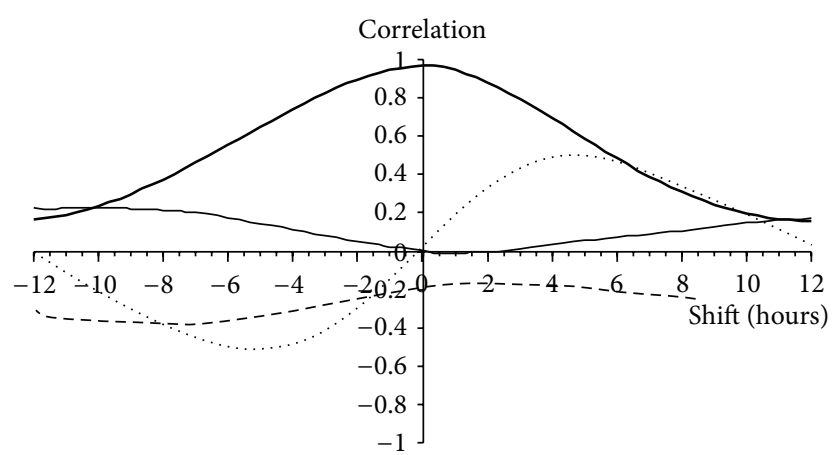

(a)

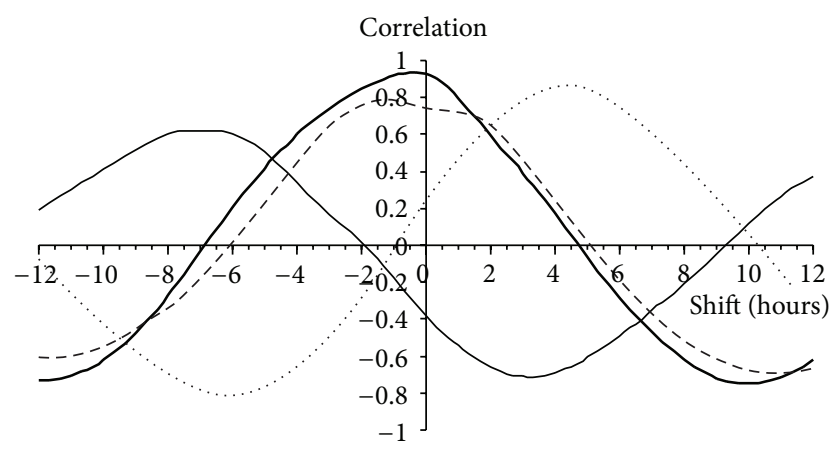

(b)

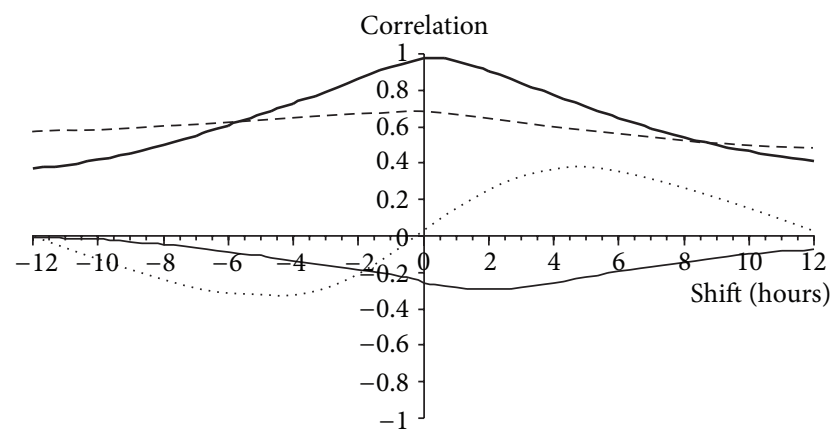

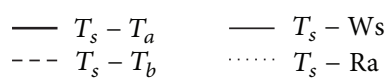

(c)

FIgURE 4: Cross correlation between the skin temperature $\left(T_{s}\right)$ and the following measured quantities in winter, summer, and autumn: air temperature $\left(T_{a}\right)$, bulk water temperature $\left(T_{b}\right)$, wind speed $(\mathrm{Ws})$, and solar radiation $(\mathrm{Ra})$.

diurnal cycle. Figure 7(c) presents the net heat flux calculated through two independent approaches, by calculating the residual or net heat flux and by calculating the changes in the heat storage (see the end of Section 2). Since the Dead Sea is fully mixed during this period of the year (holomictic conditions), the heat storage calculation is rather straightforward. The general trend of the bulk water temperature decreasing with time (Figure $7(\mathrm{e}), \sim 0.015^{\circ} \mathrm{C} /$ day) suggests that the net heat flux is directed upwards from the lake to the atmosphere, which is also confirmed by the calculated

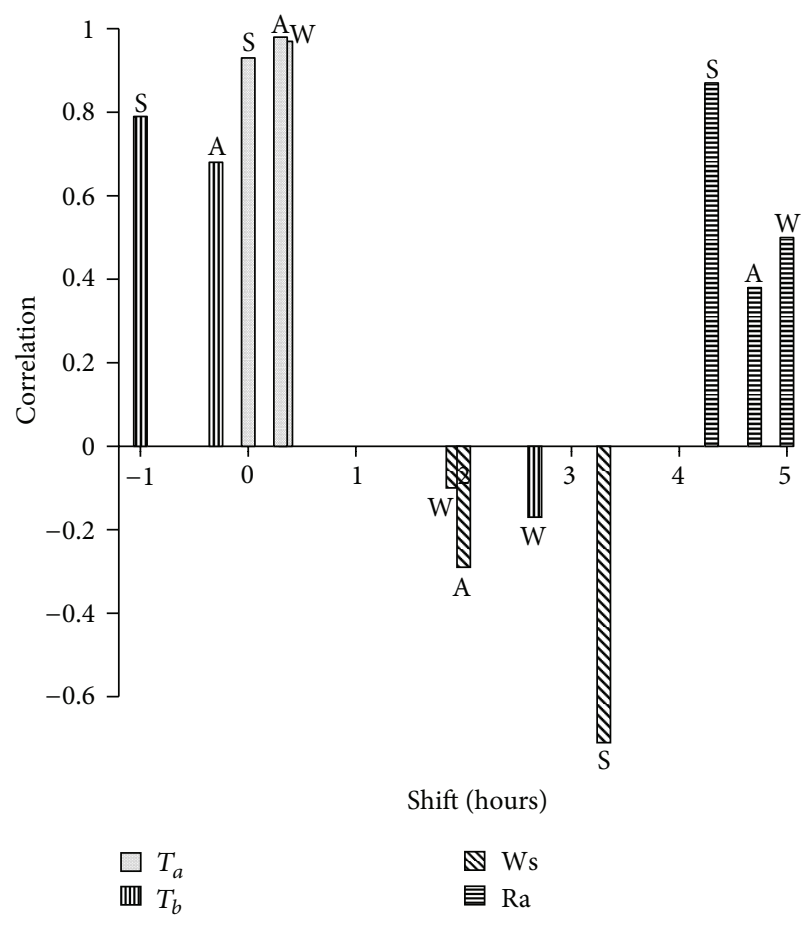

FIgURE 5: The maximum correlations from Figure 4 with the corresponding time lags. The three seasons are denoted by $\mathrm{S}$ : summer, $\mathrm{W}$ : winter, A: autumn.

net flux using the residual approach. The cooling of the Dead Sea during this period is the "engine" that drives the vertical convection, which leads to a uniform water column. Note the general agreement of the calculated net heat flux in the two independent approaches. Figures 7(d), 7(e), and 7(f) present the Bowen ratio, the air, bulk and skin temperatures, and the wind speed. The Bowen ratio is around 0.2 (Figure $7(\mathrm{~d})$ ), with diurnal changes ranging from 0 to 0.5 , with one event with a negative value (when air temperature was higher than bulk water temperature). Figure $7(f)$ presents the wind intensity through the period, influencing the latent and sensible heat fluxes (Figure 7(b) and (2)-(4)). Throughout the year $T_{s}$ is nearly uncorrelated with the latent heat flux ( 0.06 and 0.08 in summer and winter, resp.). This is not surprising since the water temperature affects the evaporation only indirectly through the computation of the saturation vapor pressure. However, $T_{s}$ is highly correlated with the sensible heat flux in summer (0.93), but somewhat less correlated in winter and autumn (0.62 and 0.66 , resp.). The sensible heat flux, according to (3), is the product of the nonlinear wind speed factor and the air-sea temperature difference, which is a linear function of the water surface temperature. From Figure 3 it is clear that $T_{s}$ and $T_{a}$ are highly correlated in all seasons and thus suggesting that the sensible heat flux is the main component of the atmospheric forcing of $T_{s}$. The lower correlations between $T_{s}$ and the sensible heat flux in winter and autumn are therefore related to the weaker dependence of $Q_{S}$ on the wind speed in these seasons (Figure 3). 


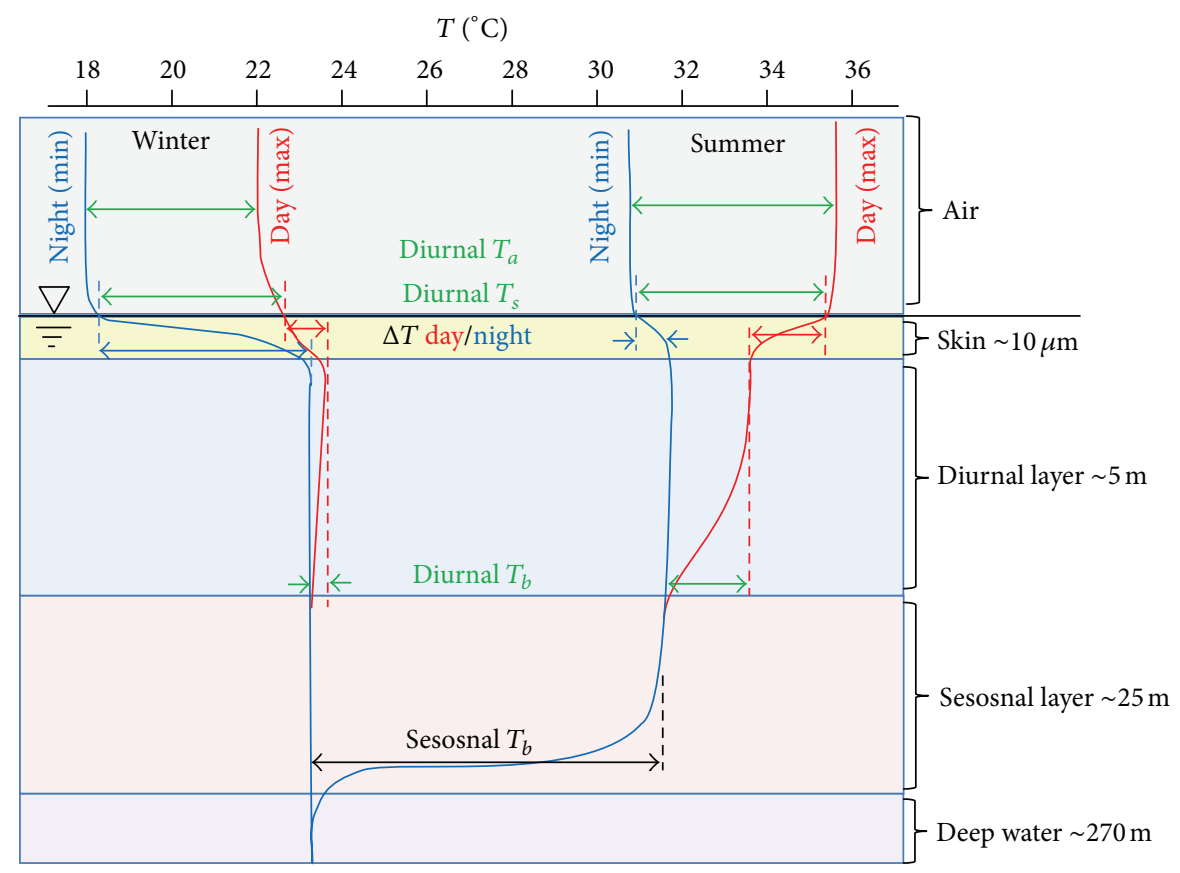

FIGURE 6: A schematic diagram showing the vertical temperature profiles including the major physical layers (air, skin, and the water column). The diurnal and seasonal variations are shown. Dotted arrows stand for diurnal variations between day (solid gray curves) and night (black curves) temperature profiles. Solid gray and solid black arrows show the day and night skin effect, respectively. The dashed arrow represents the amplitude of the seasonal thermocline.

\section{Discussion}

The magnitude of the skin effect is influenced by the diurnal cycle of solar radiation and winds [3, 4, 22]. Neohrai et al. [13] have shown that the solar radiation and wind intensity control the spatial variance of the Dead Sea SST in the diurnal and seasonal cycles. Here we show that in the Dead Sea the skin temperature is mostly correlated to the air temperature and much less to bulk water temperature, wind speed and solar radiation. Measurements were conducted from a buoy located towards the center of the lake at water depth of $60 \mathrm{~m}$ and $5 \mathrm{~km}$ offshore (Figure 1), far enough from significant influence of boundary effects (such as upwelling, downwelling, or shallow water effects) on the sea surface. Surface cooling due to wind induced upwelling events was not observed during the earlier [17] or during the more recent $[15,18]$ measurement periods; in the winter, the lake is fully mixed, and bulk water temperature is practically uniform, while, in the summer, the upper warm mixed layer reaches depth of $\sim 25 \mathrm{~m}$, and the cooler hypolimnion or metalimnion does not approache the surface (see also [15-17]). While SST in closed and stratified lakes can be influenced by wind driven upwelling events (e.g., in Lake Tahoe, [14]), this does not appear to be a significant factor in the Dead Sea as indicated by thermistor chains [15-18] and by satellite thermal images [13]. Furthermore, Sirkes [17] concluded that oscillations due to internal seiches, and their weak surface manifestation in summer, are not a result of direct wind forcing.

Figure 6 presents day/night and summer/winter schematic temperature profiles, summarizing our findings. Whereas the amplitude of the air and skin temperature diurnal cycles is similar in the summer and winter (four upper dotted arrows), the amplitude of the bulk temperature diurnal cycle is very different between summer and winter (two lower dotted arrows). The skin effect is low during summer nights and winter days while during summer days and winter nights it increases (solid black and solid gray arrows). In the summer, a daily thermocline builds up, resulting in significant amplitude of the diurnal cycle, whereas in the winter the amplitude of the diurnal cycle is very small, due to the vertical mixing. Therefore, the correlation between air and skin temperature is high in all seasons, whereas the correlation between bulk and skin temperature is higher in the summer, and no correlation was found in the winter. The highest skin effect $\left(T_{b}-T_{s}\right)$ occurs during winter nights (left black arrow), when the bulk water temperature is $\sim 24^{\circ} \mathrm{C}$, whereas the air and skin temperatures drop below $19^{\circ} \mathrm{C}$.

Figure 5 summarizes the correlations and time lags of the skin temperature and the other measured parameters. The wind intensity and the solar radiation are correlated to the skin temperature, but with a time lag of a few hours. Since the response time of the skin layer is very short (<second), it implies that solar radiation and wind intensity have an indirect effect on the skin layer. High correlations and negligible time lags between air and skin temperatures suggest that the air temperature plays a major role in the forcing of the skin temperature. This forcing is accomplished through the sensible heat flux, which is a direct linear function of the airsea temperature difference. This is also manifested in summer evenings when high air and skin temperatures decrease from 


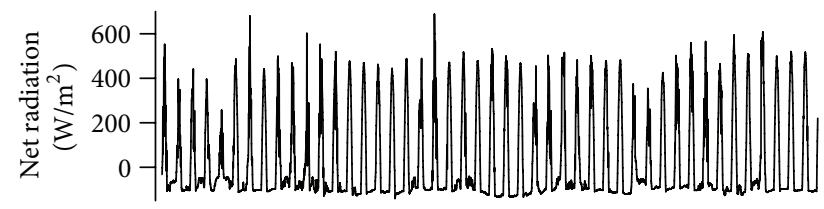

(a)

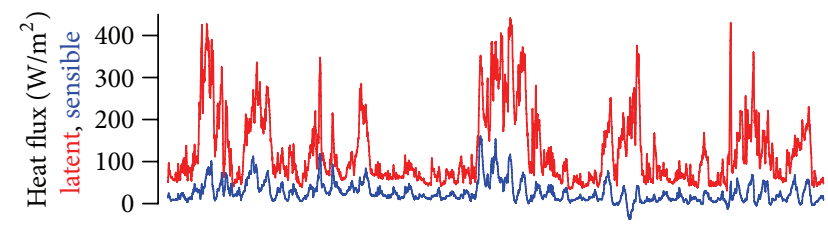

(b)

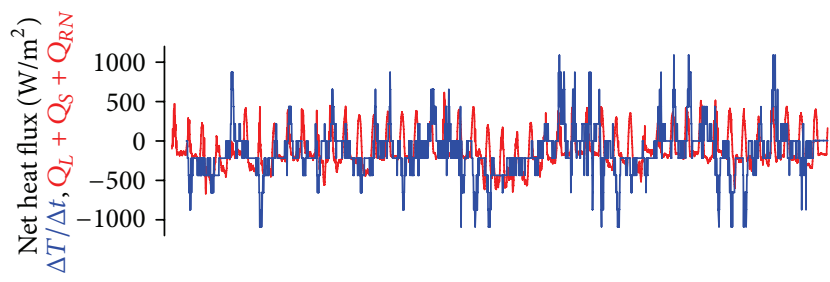

(c)

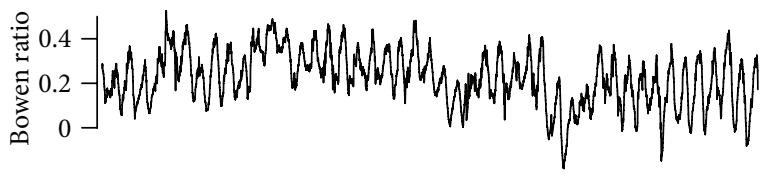

(d)

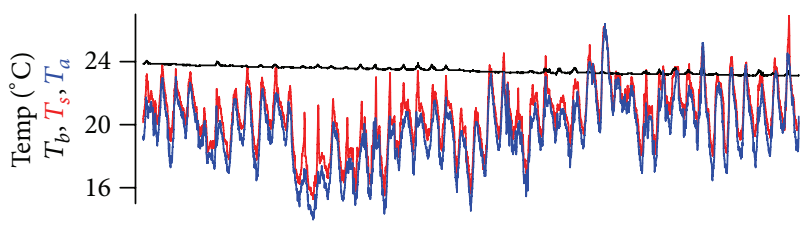

(e)

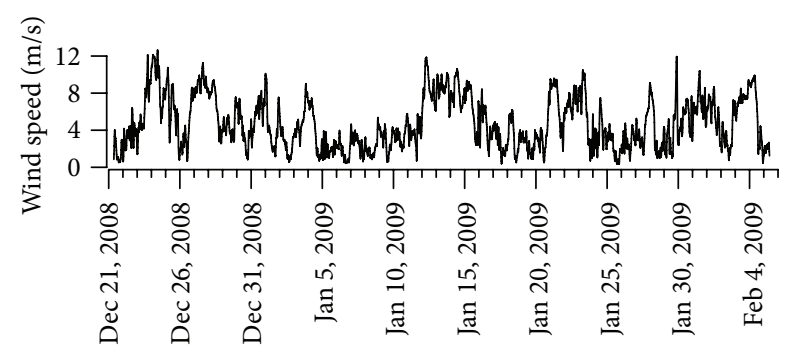

(f)

FIGURE 7: Time series of the heat fluxes at the Dead Sea surface and the governing meteorological factors, measured during wintertime.

the peak temperature only a few hours after sunset and after the bulk temperature has decreased (Figures 2(b) and 2(e)). This happens when air from the Mediterranean Sea breeze (Figure 2(e)) is heated adiabatically while descending from the Judean Mountains to the Dead Sea, delaying the evening cooling to a few hours after sunset. There is no other explanation for the high temperature of the skin layer at night other than the influence of the air temperature.
The skin layer of the Dead Sea can be classified into two mixing regimes:

(i) unstable conditions in winter when the skin temperature is controlled by free convection (where $T_{s}<T_{b}$ ). The spatial variations of SST are low in such conditions [13]. The skin layer temperature is less affected by wind since it is unstable and it continuously sinks and rebuilds. To some extent this is also the case in summer nights, when night cooling takes place,

(ii) stable conditions during the daytime in summer when the skin is affected by the stable thermal layering due to heating by solar radiation. The stable structure of the upper water layer is very sensitive to wind gusts that cause significant spatial variations [13].

\section{Conclusion}

We found that the skin temperature in the Dead Sea is most highly correlated to the air temperature in all seasons (0.93$0.98)$. In the summer, when the Dead Sea is stratified, the skin temperature is also correlated to the bulk water temperature of the surface (0.80). In the winter, however, when the Dead Sea is vertically mixed, the amplitude of the skin temperature diurnal cycle is $\sim 4^{\circ} \mathrm{C}$, whereas the bulk water shows an amplitude of $\sim 0.2^{\circ} \mathrm{C}$, and therefore there is no correlation between the skin and bulk temperatures in the winter. Low correlations were found between the skin temperature and the solar radiation and wind speed in all seasons. The skin, with its low thermal inertia, responds immediately to the governing forcing. Thus the air temperature with its highest correlation and minimal time lag is considered to be the most important factor in the forcing of the skin layer's temperature, which is accomplished primarily through the sensible heat flux.

\section{Acknowledgments}

The authors thank Isaac Gertman for supplying the in situ measurements from the buoy, which enabled this research, and for his critical reading. The authors thank Raanan Bodzin for the assistance in the field work, critical reading, and helpful discussions. Ittai Gavrieli, Vladimir Lyakhovsky, and Gerald Stanhill are acknowledged for fruitful discussions. The authors also thank Uri Malik and Shabtai Cohen for helping with the installation and calibration of the instruments, and the late Moti Gonen, Silvy Gonen, and the crew of the "Taglit" for cruise services. The authors thank Tal Ozer and Boris Katsanelson for assistance in the field. Ali Arnon is acknowledged for statistical analysis of the time series. The research was supported by the Earth Science Research Administration, the Ministry of National Infrastructures (Israel).

\section{References}

[1] W. J. Emery, S. Castro, G. A. Wick, P. Schluessel, and C. Donlon, "Estimating sea surface temperature from infrared 
satellite and in situ temperature data," Bulletin of the American Meteorological Society, vol. 82, no. 12, pp. 2773-2785, 2001.

[2] P. M. Saunders, "The temperature at the ocean-air interface," Journal of the Atmospheric Sciences, vol. 24, pp. 269-273, 2011.

[3] C. J. Donlon, P. J. Minnett, C. Gentemann et al., "Toward improved validation of satellite sea surface skin temperature measurements for climate research," Journal of Climate, vol. 15, no. 4, pp. 353-369, 2002.

[4] D. C. Oesch, J.-M. Jaquet, A. Hauser, and S. Wunderle, "Lake surface water temperature retrieval using advanced very high resolution radiometer and Moderate Resolution Imaging Spectroradiometer data: validation and feasibility study," Journal of Geophysical Research C, vol. 110, no. 12, Article ID C12014, 17 pages, 2005.

[5] C. J. Merchant, M. J. Filipiak, P. Le Borgne et al., "Diurnal warmlayer events in the western Mediterranean and European shelf seas," Geophysical Research Letters, vol. 35, no. 4, Article ID L04601, 2008.

[6] A. T. Jessup, C. J. Zappa, M. R. Loewen, and V. Hesany, "Infrared remote sensing of breaking waves," Nature, vol. 385, no. 6611, pp. 52-55, 1997.

[7] C. J. Merchant, L. A. Horrocks, J. R. Eyre, and A. G. O'Carroll, "Retrievals of sea surface temperature from infrared imagery: origin and form of systematic errors," Quarterly Journal of the Royal Meteorological Society, vol. 132, no. 617, pp. 1205-1223, 2006.

[8] C. J. Merchant, P. Le Borgne, A. Marsouin, and H. Roquet, "Optimal estimation of sea surface temperature from splitwindow observations," Remote Sensing of Environment, vol. 112, no. 5, pp. 2469-2484, 2008.

[9] S. L. Castro, G. A. Wick, P. J. Minnett, A. T. Jessup, and W. J. Emery, "The impact of measurement uncertainty and spatial variability on the accuracy of skin and subsurface regressionbased sea surface temperature algorithms," Remote Sensing of Environment, vol. 114, no. 11, pp. 2666-2678, 2010.

[10] A. T. Jessup and R. Brance, "Integrated ocean skin and bulk temperature measurements using the Calibrated Infrared in Situ Measurement System (CIRIMS) and through-hull ports," Journal of Atmospheric and Oceanic Technology, vol. 25, no. 4, pp. 579-597, 2011.

[11] E. J. Noyes, P. J. Minnett, J. J. Remedios, G. K. Corlett, S. A. Good, and D. T. Llewellyn-Jones, "The accuracy of the AATSR sea surface temperatures in the Caribbean," Remote Sensing of Environment, vol. 101, no. 1, pp. 38-51, 2006.

[12] N. G. Lensky, Y. Dvorkin, V. Lyakhovsky, I. Gertman, and I. Gavrieli, "Water, salt, and energy balances of the Dead Sea," Water Resources Research, vol. 41, no. 12, Article ID W12418, 13 pages, 2005.

[13] R. Nehorai, I. M. Lensky, N. G. Lensky, and S. Shiff, "Remote sensing of the Dead Sea surface temperature," Journal of Geophysical Research C, vol. 114, no. 5, Article ID C05021, 2009.

[14] T. E. Steissberg, S. J. Hook, and S. G. Schladow, "Characterizing partial upwellings and surface circulation at Lake Tahoe, California-Nevada, USA with thermal infrared images," Remote Sensing of Environment, vol. 99, no. 1-2, pp. 2-15, 2005.

[15] I. Gavrieli, N. G. Lensky, M. Abelson et al., "Red Sea to Dead Sea Water Conveyance (RSDSC) study: Dead Sea research team," Tech. Rep. GSI/10/2011, Tahal Group and Geological Survey of Israel, Jerusalem, Israel, 2011.

[16] I. Gertman and A. Hecht, "The Dead Sea hydrography from 1992 to 2000," Journal of Marine Systems, vol. 35, no. 3-4, pp. 169-181, 2002.
[17] Z. Sirkes, "Surface manifestations of internal oscillations in a highly stratified saline lake (the Dead Sea)," Limnology and Oceanography, vol. 32, pp. 76-82, 1987.

[18] N. G. Lensky, I. Gertman, Z. Rosentraub et al., "Alternative dumping sites in the Dead Sea for harvested salt from pond 5," Tech. Rep. GSI/05/2010, Geological Survey of Israel, Jerusalem, Israel, 2010.

[19] D. Neev and K. O. Emery, "The Dead Sea: depositional processes and environments of evaporates," Geological Survey of Israel Bulletin 41, 147 pp., 1967.

[20] K. O. Emery and G. T. Csanady, "Surface circulation of lakes and nearly land-locked seas," Proceedings of the National Academy of Sciences of the United States of America, vol. 70, no. 1, pp. 93-97, 1973.

[21] A. Hecht and I. Gertman, "Fungal life in the Dead Sea," Mycological Research, vol. 108, pp. 1106-1106, 2004.

[22] I. J. Barton, "Interpretation of satellite-derived sea surface temperatures," Advances in Space Research, vol. 28, no. 1, pp. 165170, 2001. 

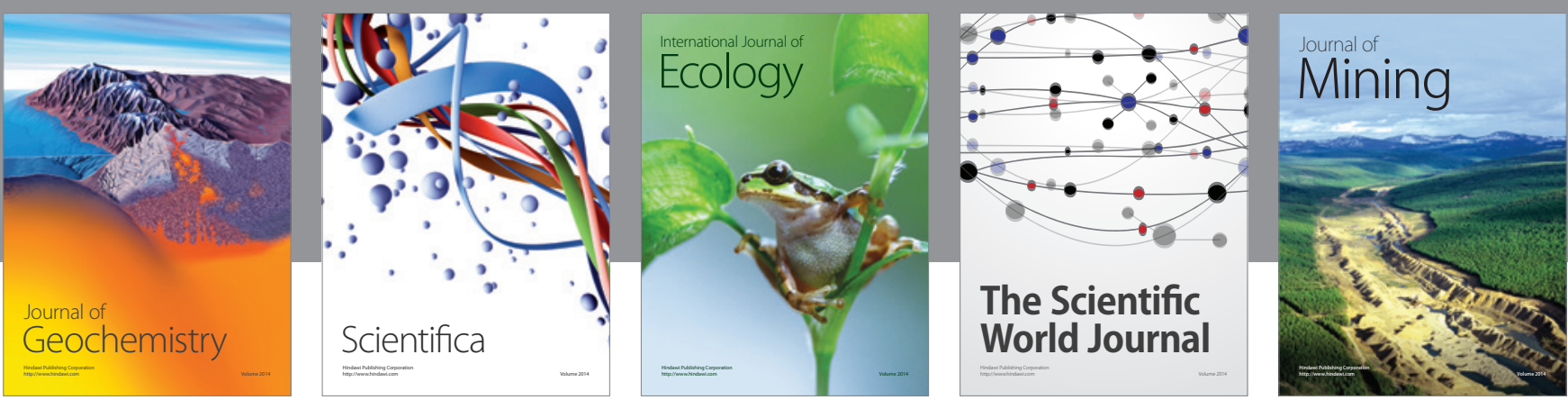

The Scientific World Journal
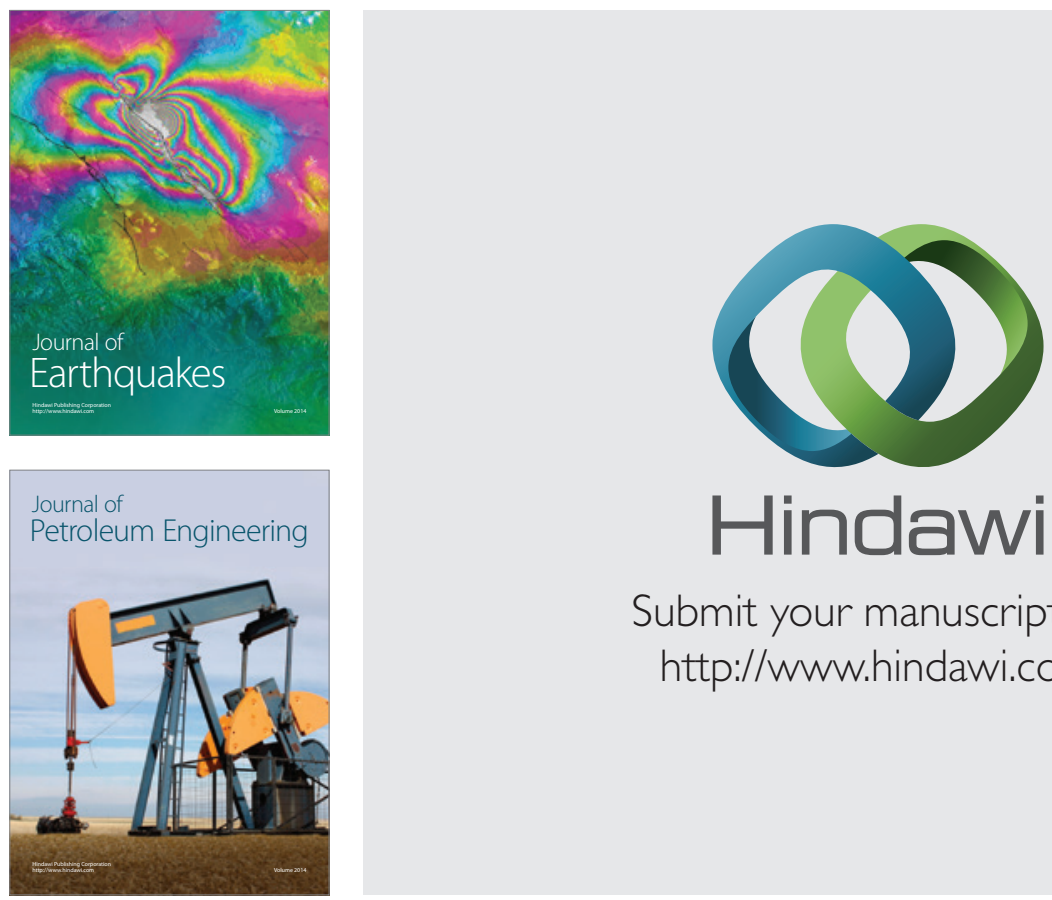

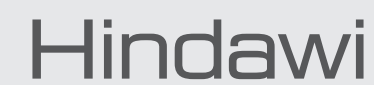

Submit your manuscripts at

http://www.hindawi.com
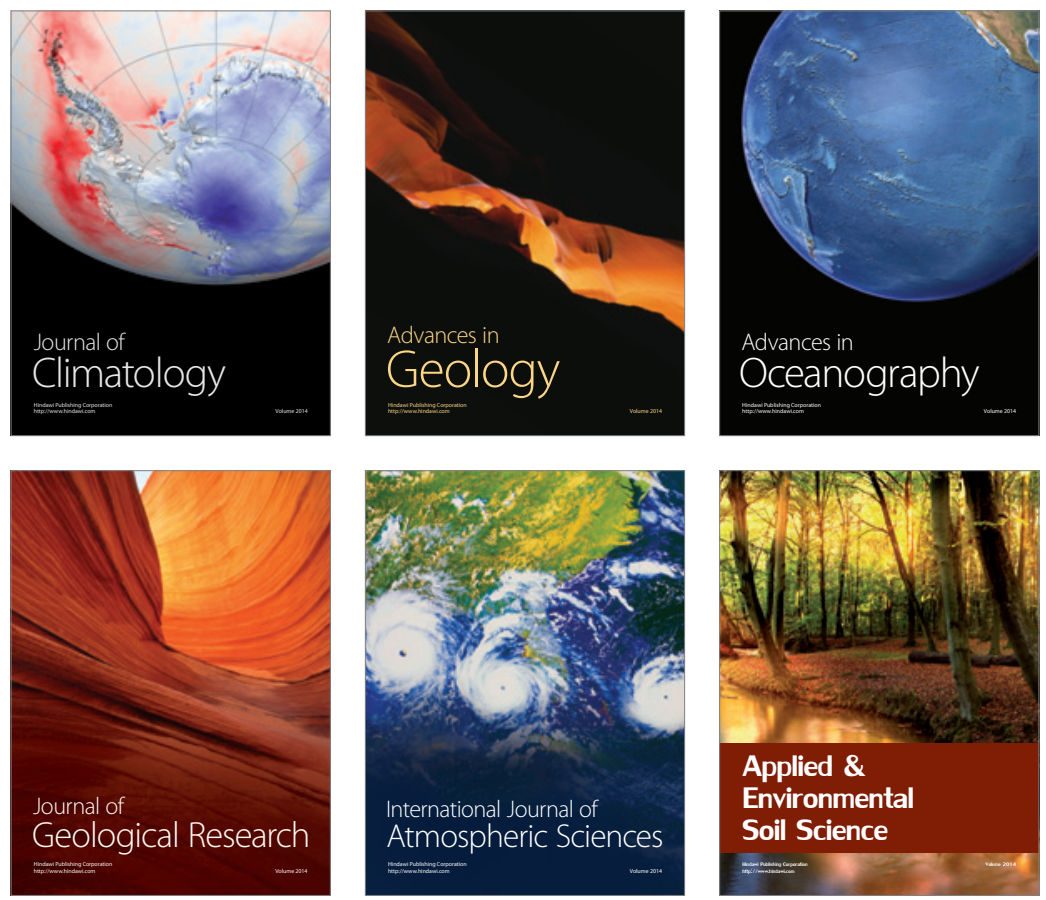
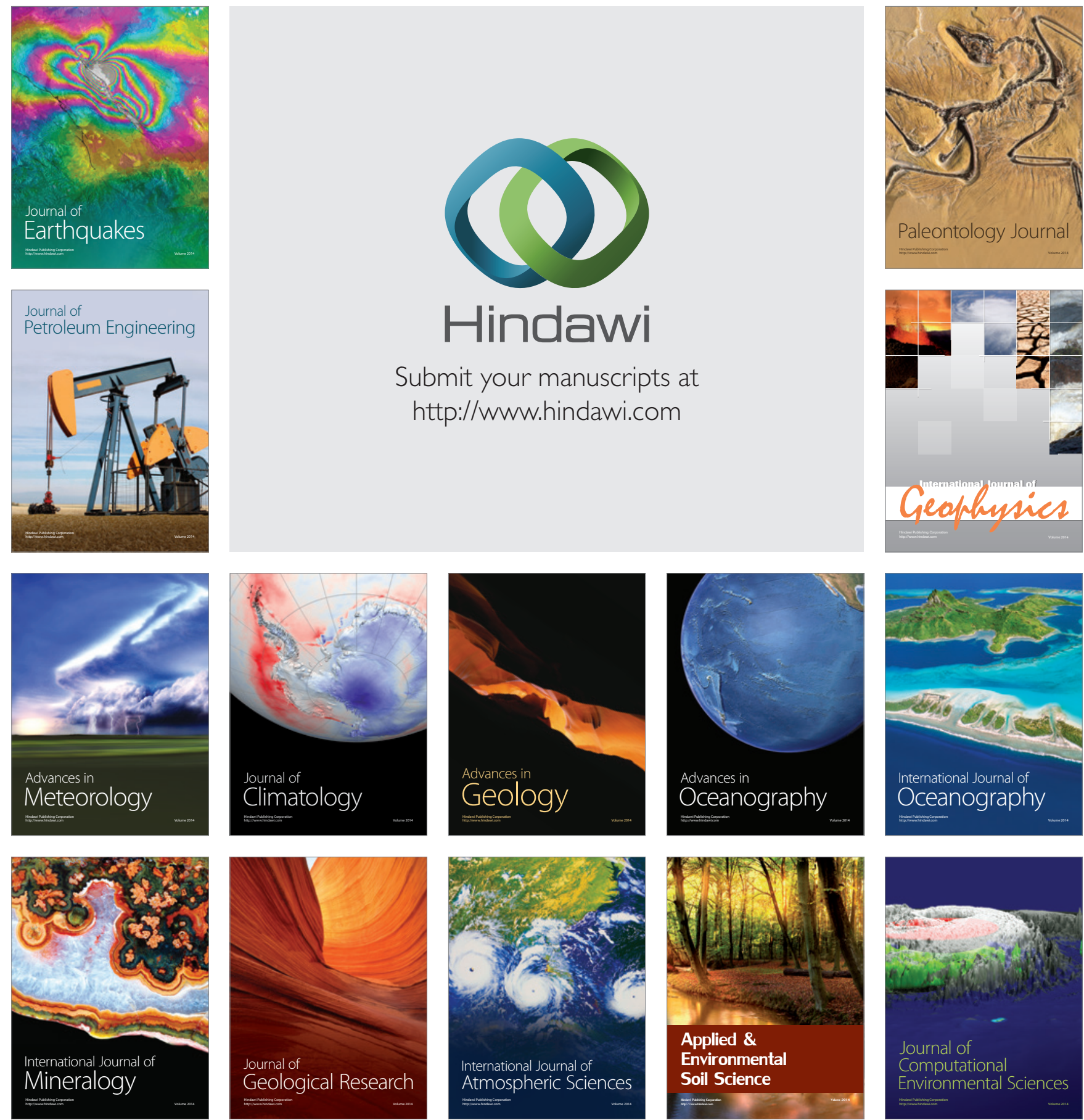